\title{
Development of first- and second-language vocabulary knowledge among language-minority children: evidence from single language and conceptual scores
}

\author{
J. Marc GOODRICH ${ }^{1 \star} \dagger$ and Christopher J. LONIGAN ${ }^{2}$ \\ ${ }^{1}$ University of Nebraska-Lincoln and ${ }^{2}$ Florida State University \\ *Corresponding author. E-mail: marc.goodrich@unl.edu \\ $\dagger$ †. Marc Goodrich, Department of Special Education and Communication Disorders, University of \\ Nebraska-Lincoln, 301 Barkley Memorial Center, P.O. Box 830738, Lincoln, NE 68583-0738.
}

(Received 31 October 2016; revised 5 May 2017; accepted 6 October 2017;

first published online 12 March 2018)

\begin{abstract}
This study evaluated the development of vocabulary knowledge over the course of two academic years, beginning in preschool, in a large sample $(N=944)$ of languageminority children using scores from single-language vocabulary assessments and conceptual scores. Results indicated that although children began the study with higher raw scores for Spanish vocabulary knowledge than for English vocabulary knowledge, this was reversed by the end of the first year of the study. Similarly, at the beginning of the study unique Spanish vocabulary scores were larger than unique English or shared Spanish-English vocabulary scores; however, by the end of the first year of the study children's shared Spanish-English vocabulary scores were larger than unique English vocabulary scores, which were larger than unique Spanish vocabulary scores. These trends continued through the second year of the study. These results suggest that conceptual scoring is a useful assessment technique for children with limited exposure to their second language. Implications for assessment and instruction are discussed.
\end{abstract}

Keywords: language-minority; vocabulary knowledge; conceptual scoring

Children who speak a language other than English at home (i.e., language-minority [LM] children), represent a large portion of the school-age population in the United States, and these children pose unique challenges to educators tasked with improving children's academic outcomes. For example, LM children in the US may first experience sustained exposure to their second language (L2), English, when they begin preschool. Although these children may have learned many words in their first language (L1) from their home language environments, they may have limited English oral language skills when they enter a formal educational setting. Theory and evidence indicate that important educational outcomes (e.g., reading comprehension) are closely linked to the development of language skills, such as vocabulary knowledge (Storch \& Whitehurst, 2002; Tunmer \& Chapman, 2012). Therefore, the purpose of this study was to examine the co-development of L1 and L2 vocabulary knowledge among young LM children.

(C) Cambridge University Press 2018 
LM children's vocabulary knowledge is dependent on their degree of exposure to L1 and L2. For example, Duursma et al. (2007) reported that LM fifth-graders' Spanish and English vocabulary knowledge were significantly correlated with measures of language use at home and school. Although many LM children in the US may not experience substantial exposure to English until preschool or kindergarten, other LM children may be exposed to both L1 and L2 at home during early childhood (Core, Hoff, Rumiche, \& Señor, 2013; Hammer, Lawrence, \& Miccio, 2008). Given the links between LM children's language exposure and their vocabulary knowledge (e.g., Duursma et al., 2007) and substantial variation in LM children's language exposure prior to school entry (Hammer et al., 2008), young LM children enter formal educational settings with varying patterns of L1 and L2 knowledge. These inter-individual differences present a number of concerns for professionals tasked with educating LM children and for identifying those children at risk for language impairment or academic under-achievement.

Although evidence indicates that exposure to English instruction is associated with increases in LM children's English vocabulary knowledge, LM children's English vocabularies still lag significantly behind those of their monolingual peers (e.g., Carlo et al., 2004; Uccelli \& Páez, 2007). Additionally, emerging evidence indicates that LM children's L1 and L2 vocabularies are not correlated (e.g., Goodrich, Lonigan, Kleuver, \& Farver, 2016; Palermo, Mikulski, Fabes, Martin, \& Hanish, 2017; Proctor, August, Carlo, \& Snow, 2006). Because of these issues, researchers and practitioners have questioned whether single language vocabulary assessment is suitable for examining the development of language skills among LM children (e.g., Bedore, Peña, García, \& Cortez, 2005). LM children typically have less vocabulary knowledge in each language than do monolingual children; however, when total scores (i.e., combined L1 and L2 vocabulary knowledge) or conceptual scores (i.e., credit given for each concept known) are used, LM children's vocabulary scores are comparable to those of monolingual children (Hoff, Core, Place, Rumiche, Señor, \& Parra, 2012; Mancilla-Martinez \& Vagh, 2013). Therefore, single-language vocabulary assessments may overestimate the prevalence of language impairment in this population (Bedore \& Peña, 2008).

To address the shortcomings of single-language vocabulary assessment, researchers advocate several alternatives, one of which is conceptual scoring. Conceptual scoring involves the administration of equivalent L1 and L2 vocabulary assessments and giving children credit for each concept that is known. For example, equivalent scores would be given to both a child who knows the English word bird but not the Spanish word pájaro and a child who knows both the English word bird and the Spanish word pájaro. Both of these children understand the concept that corresponds to the words bird and pájaro, and they receive credit for knowledge of that concept. This approach is in contrast to single-language vocabulary assessments, in which responses in the language not being assessed are scored as incorrect. Peña, Bedore, and Zlatic-Giunta (2002) reported that on a category-generation task, approximately $70 \%$ of words produced by LM children were unique to L1 or L2, and that only $30 \%$ of words were produced in both L1 and L2. This finding suggests that using conceptual scores yields information about children's language skills that would not be evident by using single-language vocabulary assessment. However, different types of language assessments (e.g., receptive vocabulary tasks) may yield different rates of word knowledge that is unique to L1 or L2 versus word knowledge that is shared across languages.

No studies to date have examined the development of components of conceptual scores over time, and it is possible that the extent to which LM children's vocabularies are distributed across languages is a function of child age or language exposure. For 
example, as children's L1 and L2 vocabulary knowledge increases, children may actively seek out labels for concepts they know in one language but not the other, leading to less distribution of vocabulary knowledge across languages. Consistent with this idea, the results of one study indicated that LM children are more likely to learn translation equivalents of words they know in one language but not the other than they are to learn words they do not know in either language (Goodrich et al., 2016). If the nature of children's L1 and L2 vocabularies changes over time, alternative assessment techniques, such as conceptual scoring, may be differentially useful at different points in development or for children with different patterns of exposure to L1 and L2.

\section{Current Study}

The purpose of this study was to describe the longitudinal development of L1 and L2 vocabulary knowledge among Spanish-speaking LM children, as well as how components of conceptual scores (i.e., unique L1 vocabulary, unique L2 vocabulary, shared L1-L2 vocabulary) change over time. To do so, we examined LM children's L1 and L2 vocabulary knowledge at four time-points over the course of two academic years, beginning in preschool. Based on theory and prior evidence (e.g., Uccelli \& Páez, 2007), we hypothesized that children would enter preschool with more Spanish than English vocabulary. Additionally, we hypothesized that children's English vocabulary would grow more over the course of the preschool and kindergarten years than would their Spanish vocabulary, because English is typically the primary language of instruction in preschools and elementary schools in the US. We expected a similar pattern of results to emerge for the components of conceptual scores. Specifically, we hypothesized that children would have more unique Spanish than unique English or shared Spanish-English vocabulary at preschool entry, but that unique English and shared Spanish-English vocabulary would grow more over the course of the preschool and kindergarten years than would unique Spanish vocabulary. Although some studies show significant cross-language relations for some early literacy skills (e.g., Lindsey, Manis, \& Bailey, 2003), we did not expect that children's L1 and L2 expressive vocabulary knowledge would be significantly related due to the distributed nature of LM children's vocabularies (e.g., Peña et al., 2002), as expressive vocabulary knowledge simply represents children's ability to produce labels for concepts. However, definitional knowledge pertaining to concepts is somewhat more language independent than is knowledge of labels for concepts. For example, with the exception of cognates, there is little relevant information from a label for a concept in one language (e.g., house) that might assist LM children in acquiring the label for that concept in their other language (e.g., casa), as lexical labels for concepts are largely arbitrary. In contrast, children may be able to express depth of knowledge (i.e., definitional knowledge) relating to a concept (e.g., for house, the fact that it is a building people live in) without knowing the specific label, as long as they know the words needed to describe it. Therefore, we expected that children's definitional vocabulary knowledge would be significantly correlated across languages.

\section{Method}

\section{Participants}

Nine hundred forty-four Spanish-speaking LM children who were recruited as part of a larger study represented the sample used for this study. Approximately half of the 
sample (48.4\%) was male, and all children spoke Spanish to some degree. At the beginning of the first year of the study (Year 1), children ranged in age from 29 to 68 months $(M=53.77, S D=5.03)$. Children were followed over the course of two academic years (e.g., preschool to kindergarten or first to second years of preschool). For various reasons (e.g., children's families moved out of the area), several children dropped out of the study. At the beginning of Year 1, 937 children completed at least one of the Spanish and English vocabulary measures, and at the end of the second year of the study (Year 2), 656 children completed at least one of the Spanish and English vocabulary measures, representing a 30\% dropout rate over the course of the two years of the study.

Children were recruited from various geographic regions across the United States, including Florida, New Mexico, California, and Kansas. Consequently, children came from homes representing a wide variety of Spanish dialects, including Mexican, Caribbean, and Central and South American dialects. Among children for whom place of birth data were available, parents reported that only 37 out of 725 (5.1\%) children were born outside the US or Puerto Rico. In contrast, among parents for whom place of birth data were available, 567 out of 682 (83.1\%) mothers and 559 out of 648 (86.3\%) fathers were born outside the United States or Puerto Rico. This indicated that the majority of LM children who participated in this study were first-generation US citizens. Among the children for whom parent report data were available, Spanish was the primary language spoken at home for approximately $78 \%$ of children, English was the primary language spoken at home for approximately $10 \%$ of children, and Spanish and English were spoken equally at home for the remaining $12 \%$ of children.

\section{Measures}

Children completed the Definitional Vocabulary subtest of the Test of Preschool Early Literacy (TOPEL; Lonigan, Wagner, Torgesen, \& Rashotte, 2007) and its Spanish translation equivalent. This subtest consisted of 35 free-response items that each had two components, a naming component and a definitional component. The naming component was analogous to typical expressive-vocabulary items in which children are shown a picture and asked, "What is this?" In the definitional component, children were asked a follow-up question that required them to describe a common feature or function of the item (e.g., "What is it for?"). The naming components of items were used to determine whether children knew a word associated with a given concept, and the definitional components of items were used to index a greater depth of knowledge pertaining to that concept. Answers were only coded as correct if they were given in the language being assessed. If children responded in the incorrect language, they were prompted to answer the question in the language being assessed. If children continued to respond in the incorrect language, the item was marked as incorrect and testing proceeded with the next item. Internal consistency reliability was very high for the Definitional Vocabulary subtest of the TOPEL $(\alpha=.98)$ and its Spanish translation equivalent $(\alpha=.96)$ in this sample.

\section{Procedure}

Written, informed consent was obtained from children's parents or guardians prior to inclusion in the study. Children completed assessments of English and Spanish vocabulary knowledge at four time-points over the two-year course of the study (i.e., 
beginning and end of Years 1 and 2). Trained bilingual research assistants administered assessments individually in a quiet area of the children's schools. Testing sessions lasted approximately 30 minutes, and Spanish and English assessments were conducted on separate days. Order of administration of Spanish and English assessments varied across participants, and Spanish and English assessments were completed no more than a week apart. In addition to evaluating Spanish and English vocabulary scores, for scores obtained from each assessment point, expressive and definitional conceptual scores were computed. Specifically, expressive and definitional scores were computed for words children knew only in Spanish, for words children knew only in English, and for words children knew in both Spanish and English.

\section{Results}

Scores from English and Spanish vocabulary assessments at each time-point are reported in Table 1. At the beginning of Year 1 children's raw scores on the measure of Spanish vocabulary were approximately 3.5 units higher than were their raw scores on the measure of English vocabulary $[t(925)=4.15, p<.001]$. Standard deviations were larger for children's English vocabulary knowledge, indicating that at the beginning of Year 1 there was more variability in English vocabulary knowledge than there was in Spanish vocabulary knowledge.

Because children's Spanish and English vocabulary knowledge differed at the beginning of Year 1, multiple regression was used to determine whether the extent to which Spanish was spoken at home uniquely predicted vocabulary knowledge at the beginning and end of the study, after controlling for the effect of child age. The percent of time that Spanish was spoken at home was not a significant predictor of English vocabulary knowledge at the beginning of Year $1(\beta=-0.02, p=.68)$ after controlling for the effect of child age $(\beta=0.24, p<.001)$. In contrast, both percent of time that Spanish was spoken at home $(\beta=0.08, p<.05)$ and child age $(\beta=0.22$, $p<.001)$ were unique predictors of Spanish vocabulary knowledge at the beginning of Year 1. Similarly, the percent of time that Spanish was spoken at home was not a significant predictor of English vocabulary knowledge at the end of Year $2(\beta=0.04$, $p=.30)$ after controlling for the effect of child age $(\beta=0.16, p<.001)$. However, both

Table 1 Descriptive Statistics for Spanish and English Vocabulary Scores across All Assessment Points

\begin{tabular}{llllll} 
& $N$ & Min & Max & Mean & $($ SD) \\
\hline English T1 & 934 & 0 & 64 & 21.90 & $(19.32)$ \\
\hline Spanish T1 & 929 & 0 & 62 & 25.38 & $(15.38)$ \\
\hline English T2 & 739 & 0 & 69 & 40.73 & $(17.05)$ \\
\hline Spanish T2 & 707 & 0 & 68 & 33.70 & $(17.96)$ \\
\hline English T3 & 719 & 0 & 69 & 46.45 & $(14.34)$ \\
\hline Spanish T3 & 661 & 0 & 68 & 33.88 & $(19.11)$ \\
\hline English T4 & 700 & 0 & 70 & 33.92 & $(10.62)$ \\
\hline Spanish T4 & 644 & 0 & 68 & 37.14 & $(18.60)$ \\
\hline
\end{tabular}

Note. $\mathrm{T} 1$ = Beginning of year 1 of study (preschool); T2 = End of year 1 of study (end of preschool for most children); T3= Beginning year 2 of study (start of kindergarten for most children); T4 = End of year 2 of study (end of kindergarten for most children). 
percent of time that Spanish was spoken at home $(\beta=0.17, p<.001)$ and child age $(\beta=$ $0.12, p<.01)$ were unique predictors of Spanish vocabulary knowledge at the end of Year 2. This pattern of results indicated that the degree to which Spanish was spoken at home was more important for Spanish vocabulary knowledge after children had been exposed to two years of English-language instruction than it was prior to preschool entry.

Repeated measures mixed-model ANOVAs indicated that both English $[F(3,2198.06)$ $=1399.26, p<.001]$ and Spanish $[F(3,2107.19)=121.20, p<.001]$ vocabulary scores increased from the beginning of Year 1 to the end of Year 2; however, the raw score increase from the beginning of Year 1 to the end of Year 2 was substantially larger for English vocabulary knowledge (approximately 32 raw score units) than it was for Spanish vocabulary knowledge (approximately 12 raw score units). Consequently, although at the beginning of Year 1 LM children in this sample had higher raw scores on the Spanish vocabulary measure than they had on the English vocabulary measure, by the end of Year 2, there was a 16-point gap in raw scores in favor of English vocabulary knowledge $[t(643)=20.16, p<.001]$. Additionally, although standard deviations for English vocabulary knowledge decreased over time, standard deviations for Spanish vocabulary knowledge increased over time, indicating that variability in English vocabulary knowledge decreased and variability in Spanish vocabulary knowledge increased over the two-year course of the study. Despite increases in English vocabulary knowledge over time, standard scores for English vocabulary knowledge were still in the low-average range at the end of Year 2 (T1 $\mathrm{M}=72.01, S D$ $=18.86 ; \mathrm{T} 2 \mathrm{M}=83.90, S D=18.47 ; \mathrm{T} 3 \mathrm{M}=83.74, S D=18.29 ; \mathrm{T} 4 \mathrm{M}=89.29, S D=$ 14.52). Standard scores for Spanish vocabulary knowledge are not available.

Conceptual scores for the separate expressive and definitional components at each assessment point are depicted in Figures 1a and 1b, respectively. For both expressive and definitional vocabulary, at the beginning of Year 1 children's unique Spanish vocabulary knowledge was larger than was their unique English vocabulary knowledge (for expressive vocabulary $t[925]=2.66, p<.01$; for definitional vocabulary, $t[925]=5.56, p<.001$ ) or their shared Spanish-English vocabulary knowledge (for expressive vocabulary, $t[925]=$ $3.75, p<.001$; for definitional vocabulary, $t[925]=5.83, p<.001$ ). Children's unique Spanish vocabulary knowledge decreased over time (for expressive vocabulary, $F[3,2091.11]=278.47, \quad p<.001 ;$ for definitional vocabulary, $F[3,2117.76]=201.11$, $p<.001$ ), whereas children's unique English vocabulary knowledge (for expressive vocabulary, $F[3,2075.13]=105.33, p<.001$; for definitional vocabulary, $F[3,2097.77]=$ 103.57, $p<.001$ ) and shared Spanish-English vocabulary knowledge (for expressive vocabulary, $F[3,2144.00]=456.55, p<.001$; for definitional vocabulary, $F[3,2149.38]=$ $476.24, p<.001)$ increased over time. By the end of Year 1 children's shared SpanishEnglish vocabulary knowledge was larger than was their unique English vocabulary knowledge (for expressive vocabulary, $t[699]=6.12, p<.001$; for definitional vocabulary $t[698]=7.06, p<.001)$, which was larger than their unique Spanish vocabulary knowledge (for expressive vocabulary, $t[699]=8.05, p<.001$; for definitional vocabulary, $t[698]=4.98$, $p<.001)$. This pattern of results persisted through Year 2.

Zero-order correlations between expressive and definitional vocabulary scores within and across languages are reported in Table 2. For expressive vocabulary (see upper panel of Table 2), within-language correlations were significant across time, indicating that individual differences in expressive language skills were stable across time. In contrast, cross-language correlations were negative or not statistically significant, indicating that there was either no relation between words known in English and Spanish, or that as the number of words known in one language 

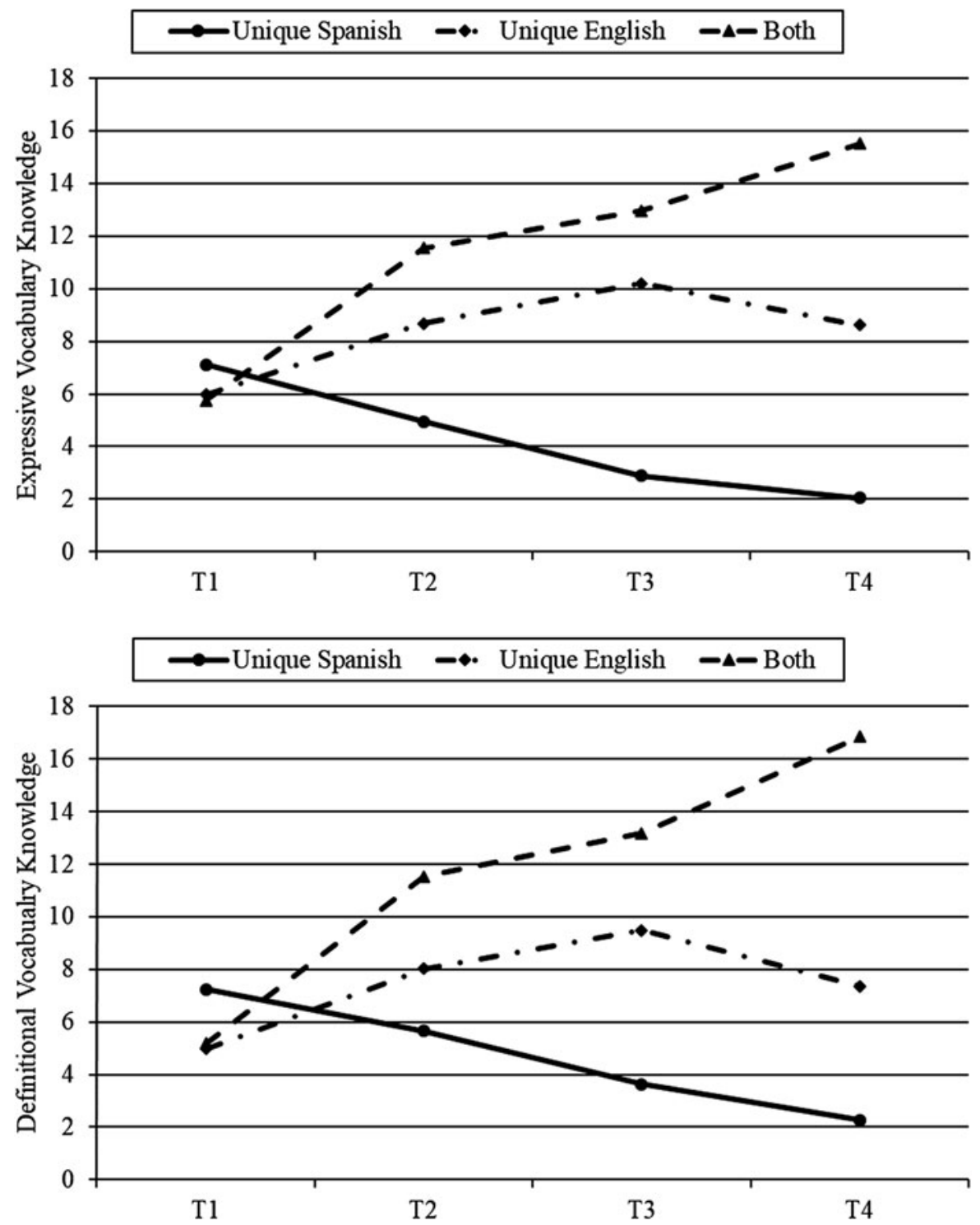

Figure 1. Components of conceptual scores from expressive (Figure 1a) and definitional (Figure 1b) at each time-point across the two years of the study.

increased, the number of words known in the other language decreased. For definitional vocabulary (see lower panel of Table 2), both within- and cross-language correlations were positive and statistically significant; however, the magnitude of within-language correlations was substantially higher than was the magnitude of cross-language correlations. This finding indicated that individual differences in definitional knowledge were stable over time and that children who had more definitional knowledge in L1 also had more definitional knowledge in L2. 
Table 2 Zero-order Correlations between Expressive and Definitional Vocabulary Scores across All Assessment Points

\begin{tabular}{|c|c|c|c|c|c|c|c|}
\hline & $\mathrm{T} 1 \mathrm{E}$ & $\mathrm{T} 1 \mathrm{~S}$ & $\mathrm{~T} 2 \mathrm{E}$ & T2 S & T3 E & T3 S & $\mathrm{T} 4 \mathrm{E}$ \\
\hline & \multicolumn{7}{|c|}{ Expressive vocabulary } \\
\hline $\mathrm{T} 1 \mathrm{~S}$ & $-.15^{\star \star \star}$ & & & & & & \\
\hline $\mathrm{T} 2 \mathrm{E}$ & $.64^{\star \star \star}$ & -.05 & & & & & \\
\hline T2 S & $-.11^{\star \star}$ & $.57^{\star \star \star}$ & -.03 & & & & \\
\hline T3 E & $.66^{\star \star \star}$ & -.04 & $.76^{\star \star \star}$ & -.07 & & & \\
\hline T3 S & $-.15^{\star \star \star}$ & $.57^{\star \star \star}$ & $-.11^{\star}$ & $.66^{\star \star \star}$ & $-.08^{\star}$ & & \\
\hline T4 E & $.51^{\star \star \star}$ & .04 & $.63^{\star \star \star}$ & .04 & $.72^{\star \star \star}$ & -.01 & \\
\hline \multirow[t]{2}{*}{ T4 S } & $-.19^{\star \star \star}$ & $.55^{\star \star \star}$ & $-.13^{\star \star}$ & $.63^{\star \star \star}$ & $-.18^{\star \star \star}$ & $.69^{\star \star \star}$ & -.06 \\
\hline & \multicolumn{7}{|c|}{ Definitional vocabulary } \\
\hline T1 S & $.11^{\star \star}$ & & & & & & \\
\hline $\mathrm{T} 2 \mathrm{E}$ & $.62^{\star \star *}$ & $.12^{\star \star}$ & & & & & \\
\hline $\mathrm{T} 2 \mathrm{~S}$ & .00 & $.52^{\star \star \star}$ & $.13^{\star \star \star}$ & & & & \\
\hline T3 E & $.60^{\star \star \star}$ & $.15^{\star \star \star}$ & $.72^{\star \star \star}$ & .03 & & & \\
\hline T3 S & -.05 & $.50^{\star \star \star}$ & .00 & $.63^{\star \star \star}$ & .06 & & \\
\hline T4 E & $.35^{\star \star \star}$ & $.23^{\star \star \star}$ & $.51^{\star \star \star}$ & $.20^{\star \star \star}$ & $.55^{\star \star \star}$ & $.14^{\star \star}$ & \\
\hline T4 S & $-.10^{\star \star}$ & $.46^{\star \star \star}$ & -.04 & $.61^{\star \star \star}$ & $-.08^{\star}$ & $.64^{\star \star \star}$ & $.18^{\star \star \star}$ \\
\hline
\end{tabular}

Note. $\mathrm{T} 1$ = Beginning of year 1 of study (preschool); $\mathrm{T} 2$ = End of year 1 of study (end of preschool for most children); $\mathrm{T} 3=$ Beginning year 2 of study (start of kindergarten for most children); T4 = End of year 2 of study (end of kindergarten for most children).

${ }^{\star \star *} p<.001 .{ }^{\star \star} p<.01 .{ }^{*} p<.05$.

\section{Discussion}

In this study, we examined the development of L1 and L2 vocabulary knowledge among Spanish-speaking LM children over the course of two academic years. Specifically, we examined the relative sizes of children's single-language vocabulary scores and unique L1 and L2 vocabulary knowledge over time, as well as whether L1 and L2 vocabulary knowledge was related. Results indicated that although children knew more words in Spanish than they did in English at the beginning of Year 1, by the end of Year 1 children knew more words in English than they did in Spanish, and the gap in vocabulary knowledge in favor of English widened over the course of Year 2. Consistent with prior research (e.g., Gathercole, Willis, Emslie, \& Baddeley, 1992), children's expressive and definitional vocabulary knowledge demonstrated high longitudinal stability within languages, and children's definitional vocabulary knowledge was moderately correlated across languages. In contrast, children's expressive vocabulary knowledge was negatively correlated across languages, a pattern of results that is consistent across several studies (e.g., Goodrich et al., 2016; Ordóñez, Carlo, Snow, \& McLaughlin, 2002). Overall, these findings have implications for the assessment and instruction of L1 and L2 vocabulary knowledge for young LM children. 
Consistent with predictions and prior research indicating that L1 and L2 vocabulary knowledge is significantly related to language exposure (e.g., Duursma et al., 2007), at the beginning of Year 1 children knew more words in Spanish than they did in English. In contrast, some studies have reported that young LM children knew more words in English than they did in Spanish (Core et al., 2013). It is possible that discrepancies in the results of this study and those of Core et al., are due to differences in the samples. The sample described in Core et al., was comprised of children who were exposed to both Spanish and English from birth, whereas parent report indicated that Spanish was the primary language spoken at home for approximately three-fourths of the children in this study. Consistent with this explanation, Hammer et al. (2008) examined vocabulary knowledge of two groups of LM children, those exposed to Spanish and English at home and those exposed primarily to Spanish at home. Results indicated that children exposed primarily to Spanish at home had greater Spanish than English vocabulary knowledge at preschool entry, whereas children exposed to both Spanish and English at home had roughly equivalent Spanish and English vocabulary knowledge at preschool entry.

Despite an advantage for Spanish vocabulary knowledge at the beginning of Year 1, growth in Spanish vocabulary lagged behind growth in English vocabulary, resulting in children having greater English than Spanish vocabulary knowledge by the end of Year 1. Although there was substantial growth in English vocabulary knowledge from Year 1 to Year 2, standard scores indicated that average English vocabulary knowledge at the end of Year 2 was below the 25th percentile (i.e., a standard score of 90), a cut-off commonly used for the diagnosis of learning disabilities (e.g., Fletcher et al., 1994). These results are consistent with those of Uccelli and Páez (2007), who reported that in kindergarten and first grade LM children knew more words in English than they did in Spanish, and that gains in English vocabulary knowledge were larger than were gains in Spanish vocabulary knowledge. These converging findings suggest that an additional focus on development of Spanish language skills (e.g., more integration of Spanish-language instruction in preschool and kindergarten, home language and literacy interventions focusing on development of Spanish language skills) may be needed to foster growth in Spanish vocabulary knowledge once children enter school; however, because this study did not evaluate the effects of language of instruction, additional research is needed to confirm any benefits of additional Spanish language instruction. Furthermore, LM children may need additional, targeted instruction designed to improve English vocabulary knowledge to begin to narrow the achievement gap with their monolingual peers (Lonigan, Farver, Nakamoto, \& Eppe, 2013).

When components of conceptual scores were examined, a pattern of results similar to the pattern of single-language L1 and L2 vocabulary development emerged. Specifically, children's unique Spanish vocabularies were larger than their unique English vocabularies or their shared Spanish-English vocabularies at the beginning of Year 1, but unique Spanish vocabularies were smaller than unique English vocabularies or shared Spanish-English vocabularies by the end of Year 1. This pattern of results suggests that many of the English words that children learned in preschool and kindergarten were words that they previously knew in Spanish, and that the English translation equivalents of Spanish words acquired during the preschool and kindergarten years were also likely to be acquired. Similarly, Goodrich et al. (2016) reported that the likelihood of acquiring an English word in preschool was significantly higher if the Spanish translation equivalent was previously known than it was if the Spanish translation equivalent was not previously known. 
Advocates of conceptual scoring often argue that single-language vocabulary assessment underestimates LM children's potential for development of vocabulary knowledge because LM children's vocabulary knowledge is distributed across the languages they are acquiring (e.g., Bedore \& Peña, 2008). At the beginning of Year 1, approximately $70 \%$ of words known by LM children in this study were known either in Spanish (38\%) or in English (32\%) but not both languages, a finding consistent with prior research (Peña et al., 2002). This finding suggests that examining unique L1 vocabulary yields information about LM children's language skills when children have had limited exposure to L2. However, as exposure to L2 increased (i.e., as indexed by length of time in preschool and kindergarten), the percent of words known uniquely in L1 decreased. By the end of Year 2, only 8\% of LM children's vocabulary knowledge was unique to Spanish $(\mathrm{M}=2.05, S D=2.72)$, suggesting that assessment of Spanish vocabulary would add little information about children's language skills that was not already accounted for by an assessment of English vocabulary. Additionally, approximately $40 \%$ of children in this sample did not know any words uniquely in Spanish at the end of Year 2, and an additional 30\% knew only one or two words uniquely in Spanish at the end of Year 2. However, consideration of whether to assess vocabulary knowledge in L1 should be determined on a case-by-case basis, as a significant number of children in this sample had large enough unique Spanish vocabulary knowledge to substantially change the standard score on the Definitional Vocabulary subtest of the TOPEL. Future research should investigate the factors that influence the shifting nature of LM children's vocabulary knowledge over time.

\section{Limitations and future directions}

Despite some strengths (e.g., large sample size, diverse population of LM children who came from various regions of the US), this study had several limitations. First, LM children's vocabulary knowledge was only examined descriptively, and therefore the results should be interpreted with caution. One theory of the development of academic knowledge and skills suggests that development of proficiency in L2 is dependent on level of proficiency in L1 at the time of sustained exposure to L2 (Cummins, 1979). In this study, children's definitional but not expressive vocabulary knowledge was significantly correlated across languages. It is possible that cross-language transfer is more relevant for certain components of language (e.g., depth of knowledge pertaining to a concept) than it is for others (e.g., knowing a label for a particular concept). Future research should examine predictors of growth in L1 and L2 language skills and examine the conditions under which LM children can utilize L1 language skills (either expressive or definitional) when acquiring L2. Similarly, the TOPEL does not include a measure of receptive vocabulary knowledge, and it is possible that patterns of L1 and L2 vocabulary knowledge differ for receptive vocabulary knowledge than for expressive or definitional vocabulary knowledge. However, recent research suggests that receptive and expressive vocabulary measures largely assess the same construct throughout the preschool and elementary school years (Lonigan \& Milburn, 2017). Second, most children in this study were exposed exclusively to Spanish at home and received English-language instruction in preschool and kindergarten. Future studies should investigate whether patterns of L1 and L2 vocabulary are similar for children in different home-language environments (e.g., L1 and L2 spoken equally often in the home) or different instructional contexts (e.g., dual language instruction, transitional bilingual instruction). Third, the measures of vocabulary knowledge used in this study were not developed specifically for populations of LM children, which may limit interpretability of 
the results. For example, words that are translation equivalents in English and Spanish do not necessarily have the same psycholinguistic properties (e.g., age of acquisition, word frequency). Therefore, Spanish-speaking LM children do not necessarily know the Spanish translation equivalents of words typically known by monolingual English-speaking preschoolers. However, it is unlikely that lexical characteristics of Spanish words had a large effect on results of this study, as English and Spanish age of acquisition $(r=.72, p<.001)$ and word frequency $(r=.53, p<.01)$ estimates for words on the Definitional Vocabulary subtest of the TOPEL were highly correlated. Nevertheless, future research should examine the simultaneous development of L1 and L2 vocabulary knowledge using measures developed for bilingual populations. Finally, this study only used measures of vocabulary knowledge as indices of language skills, and standardized vocabulary measures may have poor classification accuracy when used to diagnose language impairment (e.g., Spaulding, Plante, \& Farinella, 2006). However, the extent to which more complex measures of language provide additional information on children's language abilities beyond that provided by vocabulary measures is unclear. For example, recent studies indicate that measures of semantic and syntactic elements of language are very highly correlated from preschool through elementary school (e.g., Language and Reading Research Consortium, 2015; Lonigan \& Milburn, 2017).

\section{Conclusions}

Overall, the results of this study demonstrated that LM children show advantages in L1 vocabulary at preschool entry, but that once LM children experience sustained exposure to L2, rate of development of L2 vocabulary outpaces rate of development of L1 vocabulary. These findings suggest that conceptual scoring is a useful alternative to single-language vocabulary assessment when children have had limited exposure to L2, but that as length of exposure to L2 increases the utility of conceptual scoring decreases. As is the case for monolingual children, early identification of risk for language difficulties is important because children's L1 and L2 language skills become relatively stable early in life. Future research is needed to determine the best methods of promoting simultaneous development of language skills in L1 and L2.

Acknowledgements. This research and report was supported by grants from the Eunice Kennedy Schriver National Institute of Child Health and Human Development (HD060292 \& HD052120) and the Institute of Education Sciences, US Department of Education (R305F100027). The views expressed herein are those of the authors and have not been reviewed or approved by the granting agency.

\section{References}

Bedore, L. M., \& Peña, E. D. (2008). Assessment of bilingual children for identification of language impairment: current findings and implications for practice. International Journal of Bilingual Education and Bilingualism, 11, 1-29.

Bedore, L. M., Peña, E. D., García, M., \& Cortez, C. (2005). Conceptual versus monolingual scoring. When does it make a difference? Language, Speech, and Hearing Services in Schools, 36, 188-200.

Carlo, M. S., August, D., McLaughlin, B., Snow, C. E., Dressler, C., Lippman, D. N., ... White, C. E. (2004). Closing the gap: addressing the vocabulary needs of English-language learners in bilingual and mainstream classrooms. Reading Research Quarterly, 39, 188-215.

Core, C., Hoff, E., Rumiche, R., \& Señor, M. (2013). Total and conceptual vocabulary in Spanish-English bilinguals from 22 to 30 months: implications for assessment. Journal of Speech, Language, \& Hearing Research, 56, 1637-49.

Cummins, J. (1979). Linguistic interdependence and the educational development of bilingual children. Review of Educational Research, 49, 222-51. 
Duursma, E., Romero-Contreras, S., Szuber, A., Proctor, P., Snow, C., August, D., \& Calderón, M. (2007). The role of home literacy and language environment on bilinguals' English and Spanish vocabulary development. Applied Psycholinguistics, 28, 171-90.

Fletcher, J. M., Shaywitz, S. E., Shankweiler, D. P., Katz, L., Liberman, I. Y., Stuebing, K. K., ... Shaywitz, B. A. (1994). Cognitive profiles of reading disability: comparisons of discrepancy and low achievement definitions. Journal of Educational Psychology, 86, 6-23.

Gathercole, S. E., Willis, C. S., Emslie, H., \& Baddeley, A. D. (1992). Phonological memory and vocabulary development during the early school years: a longitudinal study. Developmental Psychology, 28(5), 887-98.

Goodrich, J. M., Lonigan, C. J., Kleuver, C. G., \& Farver, J. M. (2016). Development and transfer of vocabulary knowledge in Spanish-speaking language minority preschool children. Journal of Child Language, 43, 969-92.

Hammer, C. S., Lawrence, F. R., \& Miccio, A. W. (2008). Exposure to English before and after entry into Head Start: bilingual children's receptive language growth in Spanish and English. International Journal of Bilingual Education and Bilingualism, 11, 30-56.

Hoff, E., Core, C., Place, S., Rumiche, R., Señor, M., \& Parra, M. (2012). Dual language exposure and early bilingual development. Journal of Child Language, 39, 1-27.

Language and Reading Research Consortium (2015). The dimensionality of language ability in young children. Child Development, 86, 1948-65.

Lindsey, K. A., Manis, F. R., \& Bailey, C. E. (2003). Prediction of first-grade reading in Spanish-speaking English-language learners. Journal of Educational Psychology, 95, 482-94.

Lonigan, C. J., Farver, J. M., Nakamoto, J., \& Eppe, S. (2013). Developmental trajectories of preschool early literacy skills: a comparison of English-language learners and monolingual English-speakers. Developmental Psychology, 49, 1943-57.

Lonigan, C. J., \& Milburn, T. F. (2017). Identifying the dimensionality of oral language skills of typically developing preschool through fifth-grade children. Journal of Speech, Language, and Hearing Research, 60, 2185-98.

Lonigan, C. J., Wagner, R. K., Torgesen, J. K., \& Rashotte, C. A. (2007). Test of Preschool Early Literacy. Austin, TX: Pro-Ed.

Mancilla-Martinez, J., \& Vagh, S. B. (2013). Growth in toddlers' Spanish, English, and conceptual vocabulary knowledge. Early Childhood Research Quarterly, 28, 555-67.

Ordoñez, C. L., Carlo, M. S., Snow, C., \& McLaughlin, B. (2002). Depth and breadth of vocabulary in two languages: Which vocabulary skills transfer? Journal of Educational Psychology, 94, 719-28.

Palermo, F., Mikulski, A. M., Fabes, R. A., Martin, C. L., \& Hanish, L. D. (2017). Cross-language associations and changes in Spanish-speaking preschoolers' English and Spanish academic abilities. Applied Psycholinguistics, 38, 347-70.

Peña, E. D., Bedore, L. M., \& Zlatic-Giunta, R. (2002). Category-generation performance of bilingual children: the influence of condition, category, and language. Journal of Speech, Language, and Hearing Research, 45, 938-47.

Proctor, P. C., August, D., Carlo, M. S., \& Snow, C. (2006). The intriguing role of Spanish language vocabulary knowledge in predicting English reading comprehension. Journal of Educational Psychology, 98, 159-69.

Spaulding, T. J., Plante, E., \& Farinella, K. A. (2006). Eligibility criteria for language impairment: Is the low end of normal always appropriate? Language, Speech, and Hearing Services in Schools, 37, 61-72.

Storch, S. A., \& Whitehurst, G. J. (2002). Oral language and code-related precursors to reading: evidence from a longitudinal structural model. Developmental Psychology, 38, 934-47. New York, NY: Springer Science + Buisness Media LLC.

Tunmer, W. E., \& Chapman, J. W. (2012). The simple view of reading redux: vocabulary knowledge and the independent components hypothesis. Journal of Learning Disabilities, 45, 453-66.

Uccelli, P., \& Páez, M. M. (2007). Narrative and vocabulary development of bilingual children from kindergarten to first grade: developmental changes and associations among English and Spanish skills. Language, Speech, and Hearing Services in Schools, 38, 225-36.

Cite this article: Goodrich JM, Lonigan CJ (2018). Development of first- and second-language vocabulary knowledge among language-minority children: evidence from single language and conceptual scores. Journal of Child Language 45, 1006-1017. https://doi.org/10.1017/S0305000917000538 